\title{
Drudgery Reduction and Grip Fatigue Review of Indian Women Making Handicrafts
}

\author{
Ekta Melkani ${ }^{*}$, Manju Mehta ${ }^{2}$, Sudesh Gandhi ${ }^{3}$
}

\begin{abstract}
Indian handicrafts industry provides important segment of decentralization in India and huge employment opportunities are given to artisans including women and backward and weaker society people through this industry. Women give heavy involvement in handicraft production, but their contribution is often veiled by discourses that marginalize them providing very little critical analysis of women's handicrafts. Grip strength is a generally used to refer the physical strength or muscular power to be generated with the hands. Results at various platforms have shown significant differences for handgrip strength (in $\mathrm{kg}$ ) between male and female workers and to women majorly in handicraft sector. The repetitive nature of handicraft work causes wrist pain, grip fatigue, and other musculoskeletal disorders among women which are multiplied with house chores. The improved tools are helpful in reducing the grip fatigue and in increasing the work efficiency. Government and other supports to women in handicrafts sector are highly required to reduce the drudgery of women, to make the policies reach women with technical advancements, and to promote the traditional designs with new concepts.
\end{abstract}

Keywords: Drudgery, Grip fatigue, Handicrafts, Musculoskeletal problems, Women

Asian Pac. J. Health Sci., (2020); DOI: 10.21276/apjhs.2020.7.2.13

\section{INTRODUCTION}

Crafts production in rich cultural diversity and heritage of India is provided by unique and huge resources for the development of craft products and the country shows continuous growth rate of $20 \%$ every year. Handicrafts industry provides important segment of decentralization in India having potential Indian and international market with around 67,000 exporters. Huge employment opportunities are given to artisans including women and backward and weaker society people through this industry. The Indian Handicraft Industry is a $\$ 100$ billion industry globally, having contribution of $1.2 \%$ in world market and $1.51 \%$ share in India's exports.

Handicrafts can simply be defined as the objects made by skilled hands carrying part of the creator as well as the centuries of evolutionary traditions. India is one of the most important purveyors of handicrafts to the world trade. The Indian handicrafts production is highly labor intensive, cottage based, and decentralized which has been spread all over the country in rural as well as urban areas. ${ }^{[1]}$ Despite the rapid sociological and technical changes taking place, crafts are the integral part of India. The craft sector still today is struggling to uphold with the rising economic and political issues in India even after the developed interest of culture of crafts in designers and institutions. Handicrafts are made by the skill of the hand using no help of modern machinery or equipment. Western countries make crafts as an avocation to luxury items, but a big amount of Indian population is dependent on handicraft selling for the livelihood. There are three major classifications of crafts:

\section{Folk Crafts}

These are made by people or communities for their personal use or for the particular client base, for example, regional embroideries.

\section{Religious Crafts}

These are developed around the religious centers and themes and are related to specialized religious institutions or ceremonies, for example, temple paintings or carvings.
'PhD Scholar, Department of Family Resource Management, I.C. College of Home Sciences, CCS Haryana Agricultural University, Hisar, Haryana, India

${ }^{2}$ Professor and Head, Department of Family Resource Management, I.C. College of Home Sciences, CCS Haryana Agricultural University, Hisar, Haryana, India

${ }^{3}$ Professor (Retd.), Department of Family Resource Management, I.C. College of Home Sciences, CCS Haryana Agricultural University, Hisar, Haryana, India

Corresponding Author: Ekta Melkani, Department of Family Resource Management, I.C. College of Home Sciences, CCS Haryana Agricultural University, Hisar, Haryana, India. Email: ektamelkani@gmail.com

How to cite this article: Melkani E, Mehta M, Gandhi S. Drudgery Reduction and Grip Fatigue Review of Indian Women Making Handicrafts. Asian Pac. J. Health Sci., 2020; 7(2):54-57

Source of support: Nil

Conflict of interest: None

Received: 18/04/2020 Revised: 28/05/2020 Accepted: 04/06/2020

\section{Commercial Crafts}

These are created by specialized skill craftsmen of particular group being mastered in a particular craft, for example, the painters, dyers, or goldsmiths.

\section{Women's role in handicrafts}

Today, earnings of a common man are not sufficient for the comfortable livelihood of a family and the economy needs to get supported by family members, especially women along with gaining an advantage for a role in decision-makings. Women artisans are even sustaining the families well without taking helps from the husbands and require more support from the government for social development and productivity needs in terms of health and wealth. In the absence of proper organized set up and lack of knowledge of what tools they actually need for work efficiency, they are unable to take advantage or even to reach many schemes. ${ }^{[2]}$ 
Women give heavy involvement in handicraft production, but their contribution is often veiled by discourses that marginalize them providing very little critical analysis of women's handicrafts. The exploitative forms of production never stopped existing even by the low cost, low-risk interventions providing development projects favored by the state and non-governmental organizations. The commoditization and commercialization in women's handicrafts depend on the craftwork construction such as home-based labor and hand-power. ${ }^{[3]}$ Although it is advised to put handicrafts as a source of income-generating activities for women, the "feminine" crafts are resulted as time consuming, poor earning, and little offerings for skills' upgradation. The danger of exploitation and the burdens already borne by women can get increased if caution is avoided. ${ }^{[4]}$

\section{Affected Grip Strength among Women Artisans}

Hand strength is the major issue to be discussed among the discomforts which is a force applied by the hand to pull or suspend from objects and is a particular part of grip strength. Grip strength is a generally used to refer the physical strength or muscular power to be generated with the hands. Since the grips involve the action of a large number of different joints and muscle groups, grip strength is not always very sensitive to measure individual muscle groups in medicine. Drop of static muscular strength has been revealed out to be the most common occupational problem among handicraft workers in hand concerted jobs affecting women mostly as they are in the majority of workers. For this purpose, dynamometers have been developed that provide more specific information on individual muscles in the hand such as the Rotterdam Intrinsic Hand Myometer. Sometimes, doctors also use grip strength to test a patient's mentality, as grip strength directly correlates to mental state.

Different occupations need certain amount of grip strength and consecutively cause a certain amount of grip fatigue which can be identified through reduction in grip fatigue. Results at various platforms have shown significant differences for handgrip strength (in $\mathrm{kg}$ ) between male and female workers, and it is observed that with increase in age, significant decline occurs in handgrip strength across different age groups. Further, handgrip strength of female is mostly found significantly lower (in general, $2 / 3^{\text {rd }}$ ) than their male members that confirm the requirement of gender specific tools and design of women-friendly equipment. ${ }^{[5]}$

\section{Review of Literature}

Dhar et al. surveyed the musculoskeletal health of the workers of jewellery manufacturing sector in India. Jewellery making job requires repetitiveness, excess force, awkward posture for long duration, and contact to sharp edge and hard surface that cause work-related musculoskeletal disorder, a major contributor that affects health and productivity of the worker. A total of 358 workers of Pune were surveyed through modified NORDIC scale and physical examination that showed leading problems in region of neck (35.29\%), low back (65.27\%), knee (75.35\%), and less in shoulder $(4.75 \%)$, elbows $(8.38 \%)$, wrist $(4.47 \%)$, upper back (8.66\%), hip/thigh/buttock (0.28\%), and ankle/feet (2.23\%). About $49.01 \%$ were normal with posture other than having protruded neck with round soldiers, protruding neck only, drooping or forwarded posture as $24.90 \%, 10.28 \%, 3.56 \%, 1.58 \%$, and $5.93 \% .{ }^{[6]}$

Khan et al. found in his study that design change in the pliers reduces discomfort in the ulnar deviation and wrist extension and increases productivity. He examined that discomfort rating increased rapidly due to the influence of wrist deviation combined and forearm rotation angle, while they were $>30 \%$ joint range of motion. ${ }^{[7]}$

Dahiya et al. conducted a study on 20 bead makers of Mangali village to identify the problems and improve the condition of workers engaged in bead making activities and analyzed five major steps of bead making on the basis of physical, chemical, and environmental hazards. NORDIC scale was used to identify musculoskeletal discomfort in different body parts due to postural discomfort and found that $41.67 \%$ of respondents were engaged in bead making since $15-25$ years and $58.34 \%$ spent $6-8 \mathrm{~h} /$ day for bead making. Majority of respondents (83.34\%) adopted squatting posture in the process. High level of noise and dust/fiber create problem during prolonged working hours in awkward posture and shoulder bending. They designed a new work station for bead making on the basis of anthropometric measurements of workers of North Haryana. ${ }^{[8]}$

Mead (2011) designed a portable ergonomic workstation, substantially having multiple purpose applicability in small electronic repair, costume jewelry, factory assembly, hobbyists, craft workers and the physically challenged, etc. It included a support frame attached to an arm rest base with an arm rest pad for maintaining hand strength while accommodating multiple removable adjustable attachments and allowed optimal positioning of the upper body and the secured working materials. One embodiment of the table can also function as a standalone apparatus without attachments, in conjunction with existing non-ergonomic apparatuses or working materials while another embodiment can work when a height adjustment is not desired excluding the inclined extensions.

AICRP, Home Science, CCSHAU, Hisar (2011-2012), reported that training had been conducted in Mangali village on improved tool (bead string maker) for string making through beads. This tool saved $70.83 \%$ time of workers in comparison to traditional method and reduced postural discomfort and drudgery and increased efficiency. ${ }^{[9]}$

Maity evaluated the musculoskeletal disorders (MSDs) and postural stress among female craft workers in different districts of West Bengal. The prevalence of MSDs, body part discomfort (BPD) rating, and body joint angles of the workers along with electromyography (EMG) of the shoulder and back muscles was recorded with the BIOPAC system. The MSDs, BPD rating, and deviation of joint angle were lower while sitting on the floor with folded legs than squatting and sitting on the floor with stretched legs postures. The EMG values of the shoulder and back muscles were also lower in this posture. Hence, it was concluded that sitting on the floor with folded legs was less hazardous and imposed less postural stress with respect to other sitting postures. ${ }^{[10]}$

Gangopadhyay et al. analyzed the repetitive nature of Chikan embroidery work among female Chikan embroiderers by measurements of the prevalence upper. The repetitive nature of embroidery work was evaluated assessing the repetitive tasks (ART) of the upper limbs tool. The prevalence of wrist pain among embroidery workers was found $68 \%$ and forearm pain was $60 \%$ along with reported tingling and numbness in the hands and fingertips. The ART analysis found Chikan embroidery a highly repetitive task and concluded that embroidery workers were more likely to experience extremity pain symptoms than women in the control group. ${ }^{[1]}$

Meena et al. collected the data of hand block textile printing in small-scale textile industries of India related to musculoskeletal discomfort from 80 workers and made postural analysis using rapid upper limb assessment (RULA) technique. New design of 
hand block tool was developed using Autodesk Inventor 2014 (Educational Institute Version, i.e., V5R12) and was analyzed with HyperMesh (Version 12.0) software. Most of the workers had reported discomfort from existing hand block tool. After using ergonomics principles and anthropometric data, modifications were made in hand block tool and comparatively better and lower RULA final score of arm and wrists was observed after working with developed hand block tool. The developed hand block tool was found to be better than the existing one in terms of comfort level (42.69\% improvement) and increased production rate $(29.62 \%)$ offering improved working facility and trimmed down unwanted workplace injuries. ${ }^{[12]}$

Zulaikha suggested that innovation in the rural craft industry does not only relate to economic value but also social value. Rural craftsmen struggle to gain market because of tight competition with modern craft industries. Even after having outstanding craft skills, their limitations in producing innovative crafts make it difficult to gain market. Assistance with some top-down approach to craftspeople put them in assistance with leading designers who make them follow designers' work plan. It might be successful sometimes, but it overlooks craftsmen's capacity to reveal their uniqueness. Hence, the study proposed using bottom-up approach by making designers follow craftsmen's concept by participatory innovation approach. ${ }^{[13]}$

Mrunalini and Logeswari revealed musculoskeletal problems of the workers in unorganized jobs such as jewellery making, pottery, stone carving, metal craft work, wood carving, and patti work. About 15 studies collected from international and national journals were examined to understand the musculoskeletal problems faced by artisans, the techniques, and the interventions to assess the musculoskeletal problem suggested for relief. Nordic musculoskeletal survey schedule was used and high prevalence of musculoskeletal problems in the form of pain and discomforts in body parts were reported by the artisans. Ergonomic interventions and personal protective measures were the major reconciliations suggested in the studies. ${ }^{[14]}$

Singh and Sharma studied the demographic profile and medical history of women artisans of Lucknow in specially embroidery to measure the physiological cost of the work schedule and environment in terms of MSD and visual/postural/grip strength stress. Muscular grip strength was focussed in performing only embroidery activity. Maximum decline in handgrip strength in all groups of workers and hence types of personal protective equipment (hand gloves, finger cots, or protectors) were suggested to these workers to reduce health hazards. Back pain was the major musculoskeletal pain/discomfort reported by all units of workers. ${ }^{[15]}$

Gandhi et al. identified bead making as the most drudgery prone activity involving different activities such as chopping wood, making beads, polishing, coloring beads, and sting making. Thirty respondents from Mangali village, from West Haryana in bead making, were studied for biomechanical stress and health hazards. They had a micro tea break and lunch in-between, still stretching for $2-3 \mathrm{~h}$ in $80 \%$ sitting posture and $20 \%$ squatting posture. Cuts in fingers, saw dust in air causing eyes, and respiratory problems were the main hazards and high visual stress (80\%) was reported at the end of the day. Very severe pain in neck, head (4.9 each) shoulders, fingers (4.8 each) hands, and low back (4.6 each) led to various MSDs. A need to improve workstation and workplace environment to make it user friendly to workers was felt so the bead makers could be comfortable. ${ }^{[16]}$
Singh et al. carried a cross-sectional comparative assessment to determine the muscular strength among handicraft workers. The findings depicted the significant difference in grip strength in the right and left hands among the different occupational groups of workers exposed to hand tools for a prolonged period. The observed muscle strength in the dominant hand was relatively lower in jewelry workers while highest in block printing workers. ${ }^{[17]}$

Melkani and Mehta intervened the work and workplace of women of Mangali village of Haryana involved in various activities of bead making. Comfort was measured on ergonomic parameters with correction in environmental conditions and workstation improvement, reduction in grip fatigue (18.75\%) was observed along with reduction in overall angular deviation of body parts, improvement in OWAS and WERA measurements for body postures, improved BPDS, VAD scores, reduction in exertion through BORG, and switch to job strain index. ${ }^{[18]}$

Singh et al. made an ergonomic assessment of handgrip and pinch strength in handicraft occupation after examining 170 female participants who were handicraft (120) and office (50) workers. Hand and pinch dynamometers were used to measure their maximum static handgrip and pinch strength. It was analyzed that the findings indicating static muscular strength varied significantly due to repetitive use of hand tools. The evident decrement in pinch grip strength during hand knotting and pearl drilling was due to long cycle repetitive pinching movements of distal phalanx. The need for ergonomically designed hand tool interventions was proposed as a result that might reduce the accumulation of loss in static muscle strength. ${ }^{[19]}$

Mahato et al. discussed the quality of life of the Assam people working in the metal handicraft sector, which was improved through design intervention in tool design with application of appropriate technology. The "beading process" involved was improved with tool design intervention. Initial field study comprised the study of the existing manufacturing process, tools, and machinery involved and problems associated with the existing process to prioritize the scope of design intervention in tool design. The result after validation and testing CAD models with workers showed that newly designed tool was affordable and easy to use and could also substantially improve the quality and productivity. ${ }^{[20]}$

\section{Conclusion}

- Hand dominance is reliably correlated with hand strength, so the data provide support for about differences in strength levels between left- and right-handers and also between men and women.

- Research makes an assessment that the use of improved design tools and equipment in favor of work improvement has caused decrease in grip fatigue as well as increase in work efficiency.

- Handedness associated with handgrip strength can be differentiated using protective equipment.

- $\quad$ The grip strength can be worked on using various exercises of hands in between the tasks and the better developed workstations with other features using the height of this intervened platform can help to reduce the grip strength among women up to a certain level.

- Household drudgery directly affects the grip strength of the women artisans also during crafts working.

- There is lack of awareness about new traditions and advanced equipment among artisan women, especially in tribal areas, 
and there is a need of technological support and training through government platforms. ${ }^{[21-25]}$

\section{References}

1. Akilandeeswari SV, Pitchai C. Cooperatives and the SDGs: Focus on gender equity and women's empowerment on handicraft industry. Glob J Res Anal 2018;7:3-5.

2. AICRP. All India Coordinated Research Project on Home Science FRM Component. Participation in Bead Making Activity, Annual Report of CCSHAU Centre. Hisar (Haryana), India: Choudhary Charan Singh Haryana Agricultural University; 2011-2012.

3. Dahiya P, Singh K, Gandhi S. Workplace Improvement in Bead Making Through Ergonomic Intervention. International Conference on Ergonomics and Human Factors, HWWE; 2011.

4. Dhamija J. Women and handicrafts: Myth and reality. Seeds 1981;4:1-16.

5. Dhar U, Salve R, De A. A study of musculoskeletal health of the workers Jewellery manufacturing in India. Dev Agric Ind Ergon 2007;1:57-62.

6. Essays UK. The Contribution of Women in Handicrafts Cultural Studies Essay; 2018. Available from: https://www.ukessays.com/essays/ cultural-studies/the-contribution-of-women-in-handicrafts-culturalstudies-essay.php?vref $=1$. [Last accessed on 2020 Apr 04].

7. Gandhi S, Dilbaghi M, Mehta M. Occupational health hazards in bead making activity. In: SOUVENIR Gender Issues and Socio-Economic Perspectives for Sustainable Rural Development (GIRD). Gurgaon, India: Earth Vision Publications; 2017. p. 253-4.

8. Gangopadhyay S, Chakrabarty S, Sarkar K, Dev S, Das T, Banerjee S. An ergonomics study on the evaluation of carpal tunnel syndrome among Chikan embroidery workers of West Bengal, India. Int J Occup Environ Health 2015;21:199-206.

9. Hashmi SK. Market for Indian handicrafts. Excel J Eng Technol Manag Sci 2012;1:1-7.

10. Available from: https://www.ukessays.com/essays/economics/ handicrafts.php. [Last accessed on 2020 Mar 10].

11. Available from: https://www.indianmirror.com/crafts/crafts.html. [Last accessed on 2020 May 14].

12. Available from: https://www.handweb.eu/RIHM. [Last accessed on 2020 Mar 23].

13. Khan AA, O'Sullivan LW, Gallwey TJ. Effects of combined wrist deviation and forearm rotation on discomfort score. Ergonomics
2009;52:345-61.

14. Mahato KK, Kalita PC, Das AK. Design and development of affordable tool for metal handicraft. In: Chakrabarti A, editors. Research into Design for a Connected World. Smart Innovation, Systems and Technologies. Vol. 134. Berlin: Springer; 2019. p. 357-67.

15. Maity P, Pal A, Dhara PC. Evaluation of Work Related Musculoskeletal Disorder and Postural Stress of brick Kiln Workers during Performing Different Brick Making Task. Proceedings of HWWE: Ergonomics for Rural Development. Midnapore: Vidyasagar University; 2013. p. 386-98.

16. Meena ML, Dangaych GS, Bhardwaj A. An ergonomic approach to design hand block tool for textile printing handicraft industry. Int J Recent Adv Mech Eng 2015;4:19-30.

17. Melkani E, Mehta M. Thesis: Work and Workplace Interventions for Enhancing Comfort and Productivity of Workers for Making Bead Product; 2019. Available from: http://www.krishikosh.egranth.ac.in/ handle/1/5810137889. [Last accessed on 2020 Apr 04].

18. Mrunalini A, Logeswari S. Musculoskeletal problems of artisans in informal sector a review study. Int J Environ Ecol 2016;1:163-70.

19. Patel T, Sanjog J, Karmakar S. Isometric handgrip strength of agricultural workers from Northeast Region of India. Agric Eng Int 2015;17:130-40.

20. Singh AK, Meena ML, Chaudhary $H$. Measuring static muscular strength among female operatives: A cross-sectional comparison in different handicraft occupations. Int J Occup Saf Ergon 2018;19:1-12.

21. Singh AK, Meena ML, Chaudhary H, Dangayach GS. A comparative assessment of static muscular strength among female operative's working in different handicraft occupations in India. Health Care Women Int 2019;40:459-78.

22. Singh P, Sharma P. Thesis: Musculoskeletal Disorders and Related Health Hazards in Women Working in Chikankari Industry; 2016. Available from: http://www.krishikosh.egranth.ac.in/handle/1/5810010833. [Last accessed on 2020 Apr 04].

23. Weber CW. Women, Work and the Imagination of Craft in South Asia. Contemp South Asia 2004;13:287-306.

24. Ziyagil MA, Gürsoy R, Dane Ş, Türkmen M, Çebi M. Effects of handedness on the hand grip strength asymmetry in Turkish athletes. Compr Psychol 2015;4:2-6.

25. Zulaikha E. Reframing participatory innovation in collaboration with rural craftsmen. In; Valkenurg R, Dekkers C, Sluijs J, editors. Proceedings: Reframing Design: Design as a Mediating Activity. Vol. 4. Southern Denmark: The Hague University of Applied Sciences; 2015. p. 352-9. 